\title{
Adherence to Healthcare Waste Management Guidelines among Nurses and Waste Handlers in Thika Sub-county- Kenya
}

\author{
Njue, P. Mwaniki ${ }^{1}$, Cheboi, K. Solomon ${ }^{2}$, Oiye Shadrak ${ }^{3}$
}

\begin{abstract}
BACKGROUND: Despite the set guidelines on Healthcare Waste Management in Kenya, mixing of different categories of waste, crude dumping and poor incineration are still a common phenomenon in public health facilities in Thika Subcounty, Kenya. Thika Subcounty generates 560 Kilograms of healthcare waste daily, which is risk to the many patients (admission rate of 26\%). This may pose a potential environmental risk and be a source of disease diffusion. This research explored the adherence to healthcare waste management waste guidelines in health care facilities among the nurses and waste handlers.

METHODS: This was a cross sectional survey in which mixed methods were applied. A census and proportionate random sampling method were used. Quantitative data was analyzed using Statistical Package for Social Science (SPSS) version 20.0, while qualitative data was analyzed manually into themes.

RESULTS: Full adherence to the seven waste disposal guidelines was low (16.3\%). Knowledge on waste segregation, waste separation then disposal and means of transports were statistically significant in relation to adherence. The type of incinerator and burning status, protection maintenance and supply of adequate waste bins were also important to adherence level.

CONCLUSION: Adherence level was low (16.3\%,) and insignificantly different among nurses and waste handlers. From this finding, compliance remains a key challenge. Strategies targeted at contextualizing waste regulations and guidelines into local settings are necessary and important. Policy makers may design and implement standard incinerators across all the health facilities. This study is not exhaustive; therefore, it is necessary to carry out a study linking poor treatment and disposal of clinical waste to purported health outcomes in Kenya.
\end{abstract}

KEY WORDS: Adherence, healthcare waste guidelines, nurses, waste handlers

DOI:http://dx.doi.org/10.4314/ejhs.v25i4.2

\section{INTRODUCTION}

The management of medical waste is very critical due to its potential environmental hazards and public health risks (1). Medical waste is material produced in the course of health protection, medical treatment and scientific research (2). It consists of a broad range of materials from used needles and syringes to soiled dressings, body parts, diagnostic samples, blood, chemicals, pharmaceuticals, medical devices and radioactive materials (3). Recognizing the dangers and the negative impact of hospital waste on the public health and the environment, many countries have developed legal frameworks to guide the management of health care waste treatment (3). In Kenya, the Environmental Management and Coordination Act (EMCA) of 1999 was developed to provide a legal framework for health care waste

\footnotetext{
${ }^{1}$ Ministry of Health, Public Health Nairobi, Kenya

${ }^{2}$ National Museums of Kenya, Centre for Biodivesirty, Nairobi, Kenya

${ }^{3}$ Great Lakes University of Kisumu - TICH, Nairobi, Kenya

Corresponding Author: Cheboi, K. S., Email: solocheboi@gmail.com
} 
management practices in the country (4). National Health Care waste management standard practices; Kenya Quality Model to regulate standards and a training programme known as "DO NO HARM" for all health workers in both public and private facilities in Health Care Facilities were also launched in 2008 to compliment the framework (4). The EMCA law of 1999 insists that medical waste should either be packaged in clearly labeled bags or sterilized before disposal into any of the licensed incinerators. It further stipulates that the waste separation and packaging should be done at the health facility and that it is the responsibility of facilities to properly manage their hospital waste $(4 ; 5)$. Despite these guidelines, mixing of different categories of waste, crude dumping and poor handling of waste are still common in public health facilities in Thika Subcounty (6). Thika Subcounty generates $560 \mathrm{Kgs}$ of waste daily, which is a very high quantity and poses a potential risk to the environmental (7) and to the many patients (admission rate of 25\%) (8). A study conducted in Kenya showed that the country was still way below the World Health Organization (WHO) recommended standards, where $80 \%$ of waste should be non-infectious and can be

\section{METHODS AND MATERIALS}

This was a cross-sectional descriptive study that used both quantitative and qualitative methods of data collection. The study populations were nurses and waste handlers based in all the 34 public healthcare facilities. During the study period, the total number of nurses was 286 , while waste handlers were 114.

Sampling techniques and sample size calculations: A census method and proportionate random sampling were used. Census was applied for all waste handlers and nurses in lower facilities than the district hospital to ensure consistent ratio of waste handlers to nurses. For instance, in the district hospital, the ratio of waste handlers to nurses was 1:2, while lower facilities was 1:1 (10). Therefore, a total of 286 health workers (114 waste handlers and 172 nurses) were sampled. In the district hospital, which had 230 nurses, a two stage sampling method was used, proportionate and random sampling, to determine the number of nurses from each department. Since the district Hospital has twelve (12) departments, a recommended to join the municipal waste stream, while $20 \%$ is the infectious waste that requires special waste treatment methods (7).

According to a study done by the Ministry of Health (2008), in which hospitals were randomly selected from each province in Kenya, it revealed that provision of personal protective equipment (PPE) was poor at $37 \%$ (7). In many waste treatment sites where waste handlers had PPE; most of those found handling waste did not have them on but wore them on noticing visitors (Ibid). According to evaluation done on 17 health facilities in Thika Subcounty, waste handlers and nurses registered a higher proportion (78\%) compared to $(32 \%)$ other cadres in mismanagement of waste (9). Medical waste affects the health workers, patients, waste handlers and the community at large (10). The Waste handlers and nurses are not adhering to the waste disposal guidelines despite the clear policy. However, the reasons as to why, are not known (11). This study was undertaken focusing on adherence to the medical waste guidelines and underlying reasons on public health care facilities in Thika Subcounty.

proportionate sampling was further used to get the actual number from each.

Research instruments: For triangulation, observation check list, Key informant interview guide (KIIs), Focus Group Discussion (FGD) and Questionnaire for quantitative data. The structured questionnaire generated data on individual characteristics, knowledge, practices and adherence to medical waste guideline. The FGD provided in-dept information on why discussants practice crude dumping of waste, mixing of different categories of waste and poor incineration of waste. The FGDs was moderated by a facilitator and recorded by two rapporteurs. An FGD ranged between 8-12 participants. For homogeneity, diversity was embraced during selection. KIIs were accorded to hospital matrons, public health officers and waste handlers in charge. The KIIs centred on management role in adherence to medical waste guidelines. Observation assessed practices at institutional level in terms of waste segregation, storage, transportation and final disposal. 
Data management and analysis: A research team was trained on the setting, objectives, procedures and research ethics including pre-testing. The quantitative data were entered and analyzed for significance at alpha of value $(<0.05)$ using Statistical Package for Social Scientists (SPSS) version 20 . The results are presented descriptively and inferentially. Qualitative data were summarized in cards and categorized into themes. The data were then entered into tally sheet and edited manually.

Ethical considerations: All codes of ethics and ethical review were observed in the process of protocol development, data collection and reporing. This included explaining the purpose and objective of the study to respondents before seeking written informed consent. Authorization to carry out the study was obtained from authorities in Kenya (National Cuncil for Science, Technology and Innovation and Great Lake University of Kisumu).

\section{RESULTS}

Socio-demographic characteristics: The data were obtained from 263 participants short of the 286 due to inconsistence in some of the response to the items of the questionnaires. The mean age was thirty-five (35.1 \pm 6.63$)$, average income was Ksh.18, $000(17760 \pm 7000.19)$ and average years of service seven $(7.41 \pm 6.65)$.
Adherence to medical waste guidelines: Handling, identification, segregation, storage, transportation and final disposal are vital steps for safe and scientific management of biomedical waste (12). Success in waste management can be achieved when staff dedicate themselves to surmounting the challenges that are experienced in the areas mentioned (7). Adherence to medical waste guidelines among health workers was measured by enquiring whether the respondent had adopted the seven recommended waste disposal guidelines (Figure 1) in their work place while disposing medical waste. The study found that forty three $(16.3 \%)$ respondents fully adhered to the seven waste disposal guidelines out of which twenty one were nurses and remainder was waste handlers (Table 1). There was near proportionate distribution across the three levels of adherence among nurses, waste handlers and the combined category. In adherence to the seven key waste disposal guidelines, there was a significant difference in health worker category in relation to correct storage of waste $(p=0.009)$ and use of personal protective equipment $(\mathrm{p}=0.031)$ not in the other five waste management guidelines ( $p>0.05)$. This finding was complemented by themes from qualitative report, which reported that it is healthy to handle waste with gloves. This was candidly expressed by one FGD discussant that "It looks unaesthetic to handle soaked blood gauzes without wearing gloves since one can be exposed to disease and germs".

Table 1: Adherence to the medical waste guidelines $(\mathrm{n}=263)$

\begin{tabular}{lllllll}
\hline Job Title & \multicolumn{2}{l}{ Health worker category (n) $(*$ \%) } & & & \\
& Full* & Partial* $^{*}$ & None $^{*}$ & $\chi^{2}$ & df & P value \\
\hline Nurse & $21(13.0)$ & $135(83.3)$ & $6(3.7)$ & 3.984 & 2 & 0.136 \\
w/operators & $22(21.8)$ & $74(73.3)$ & $5(5.0 \%)$ & & & \\
\hline
\end{tabular}

Abbreviations: $n=$ number of respondents: *row percentages 


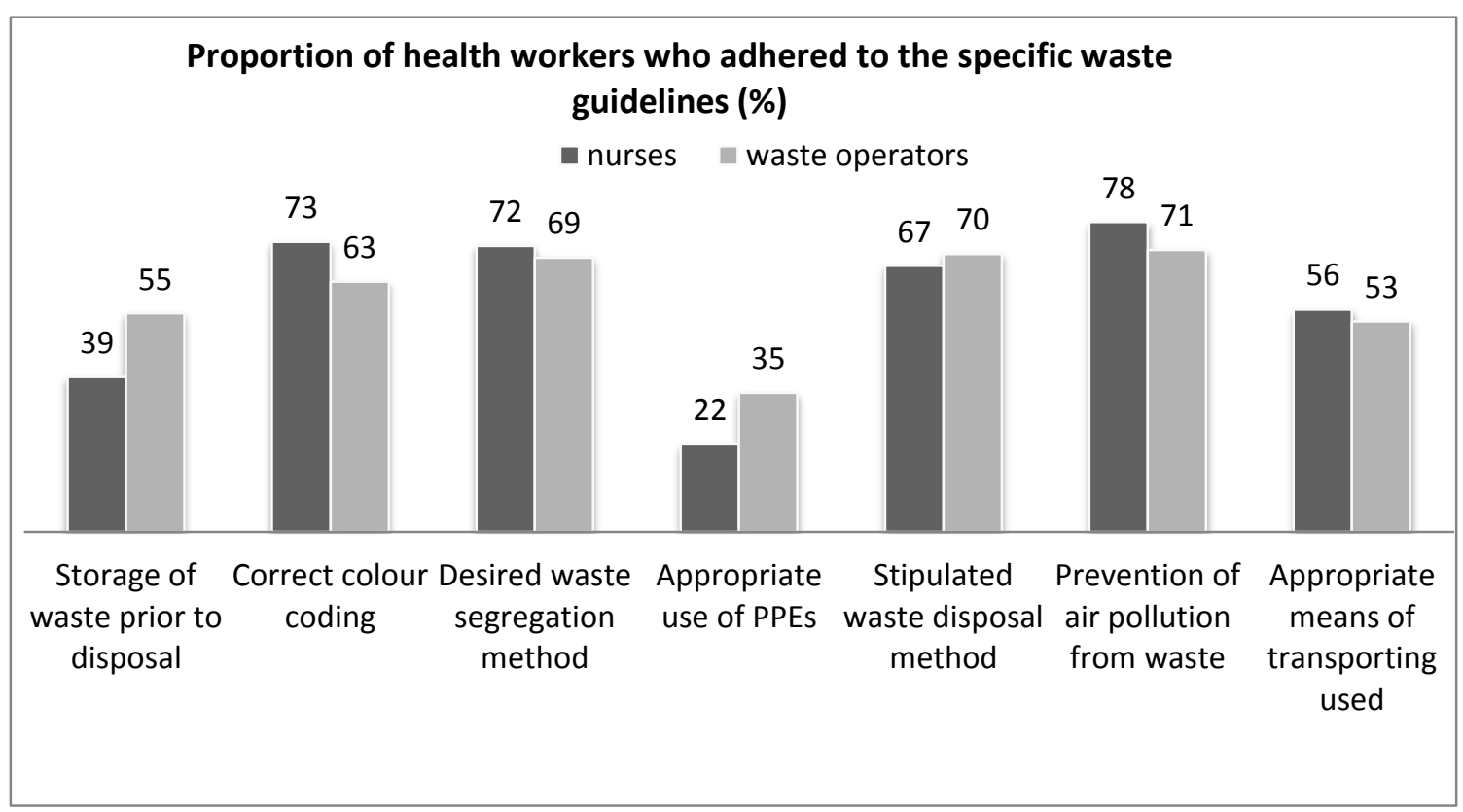

Figure 1:Adherence to the seven specific medical waste guidelines among health workers

\section{Knowledge on waste segregation}

Over $75 \%$ of the participants demonstrated some knowledge of waste segregation with diseases prevention, avoiding needle pricks/injury and aesthetic values as the central reasons for segregation while few named recycling. Method of waste segregation was significant in relation to adherence. Majority of the respondents who adopted colour coding method, full and partial adhered to the guidelines. This conformed to themes from FGD that supervisors are keen on observation of safety all the times. One discussant acknowledged "The facility public health officer reprimands a person if he finds any mess concerning medical waste segregation and therefore we try as much to avoid this".

On types of medical waste generated, there was a significant categorical difference among nurses and waste handlers in knowledge of highly infectious waste $\left(\chi^{2}=20.039, \mathrm{df}=1, \mathrm{p}=0.000\right)$, infectious waste $\left(\chi^{2}=10.195 \mathrm{df}=1, \mathrm{p}=0.001\right)$ and toxic waste $\left(\chi^{2}=9.073 \mathrm{df}=1, \mathrm{p}=0.003\right)$ with positive biase on nurses. Parity was observed in knowledge on general waste and legal implications of mismanagement of waste . Nurses $(82.7 \%)$, are aware of stipulated medical disposal guidelines than waste handlers $(68 \%)$ and segregating waste to prevent diseases and this chimed well with qualitative findings that nurses are more technical than waste handlers. "You know most waste handlers are employed on casual basis and so, most of them are not trained on medical waste guidelines, hence the reason for this mess around", concluded one Kii informant.

\section{Medical waste disposal practices}

Several (75\%) of the respondents complied in regards to separations of waste, disposal of sharps, papers and segregation at the sources (Figure 2). However, both reported average results in disposal of body fluids and toxics. Knowledge on stipulated waste guidelines, legal implication of mismanagement of waste, types of waste and management plan influenced adherence while knowledge transportation and reason for segregating did not (Table 2). 


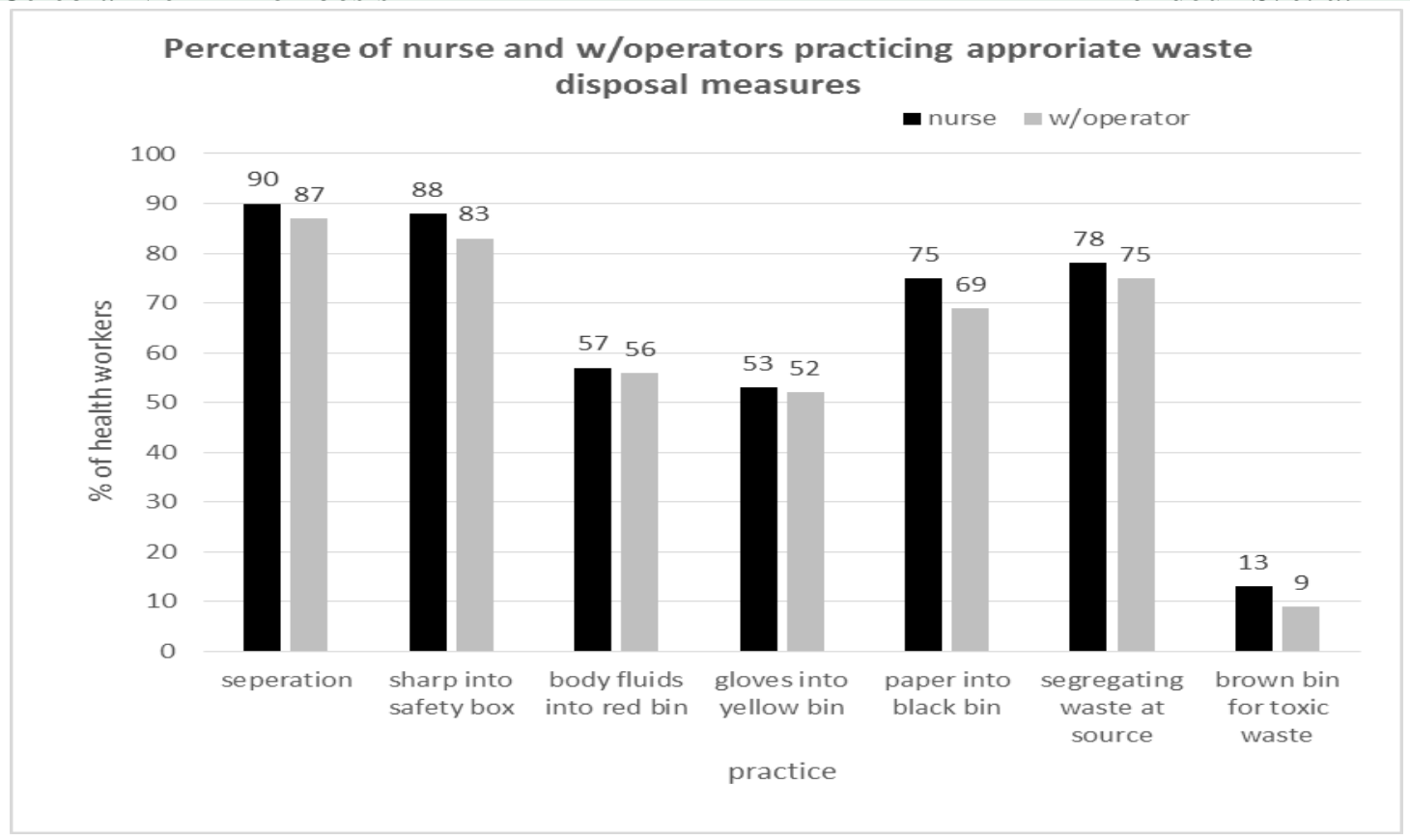

Figure 2: Appropriate waste disposal practices

Table 2: Knowledge and practice influence on adherence to waste disposal guidelines

\begin{tabular}{|c|c|c|c|c|c|c|}
\hline \multirow[t]{2}{*}{ Factor } & \multicolumn{3}{|c|}{ Adherence $(\mathrm{n}=263)(* \%)$} & \multicolumn{3}{|c|}{ Bivariate analysis } \\
\hline & Full & Partial & None & $\chi^{2}$ & $\mathrm{df}$ & $\mathbf{P}$ value \\
\hline \multicolumn{7}{|c|}{ Know waste guideline } \\
\hline Yes & $43(21.2)$ & $152(74.9)$ & $8(3.9)$ & 21.088 & 2 & $<0.0001$ \\
\hline No & 0 & 57 (95.0) & $3(5.0)$ & & & \\
\hline \multicolumn{7}{|c|}{ Know all waste categories } \\
\hline Yes & $20(32.3)$ & $41(66.1)$ & $1(1.6)$ & 15.654 & 2 & $<0.0001$ \\
\hline No & $23(11.4)$ & $168(83.6)$ & $10(5.0)$ & & & \\
\hline \multicolumn{7}{|l|}{ Prosecution } \\
\hline Yes & $39(20.2)$ & $146(75.5)$ & $8(4.1)$ & 8.766 & 2 & 0.010 \\
\hline No & $4(5.7)$ & $63(90.0)$ & $3(4.3)$ & & & \\
\hline \multicolumn{7}{|c|}{ Separating then disposal } \\
\hline Yes & 41(17.6) & $186(79.8)$ & $6(2.6)$ & 10.649 & 2 & 0.003 \\
\hline No & $2(6.7)$ & $23(76.7)$ & $5(16.7)$ & & & \\
\hline \multicolumn{7}{|c|}{ Means of transports } \\
\hline Wheel barrow & $42(29.4)$ & $101(70.6)$ & 0 & 53.335 & 6 & $<0.0001$ \\
\hline Sack & 0 & $17(89.5)$ & $2(10.5)$ & & & \\
\hline By hand & 0 & $59(92.2)$ & $57.8)$ & & & \\
\hline Carton & 0 & $21(95.5)$ & 0 & & & \\
\hline
\end{tabular}

Abbreviations: $\mathrm{n}=$ total number of respondents, $\mathrm{CI}=$ confidence interval; ${ }^{*}$ Column percentages, significant fisher exact test $\mathrm{p}$ value in bold

Institutional factors and adherence to waste disposal guidelines: The type of incinerator, burning status, protection and maintenance were statistically significant in relation to respondents' adherence level. Majority (80\%) of the respondents with full adherence were associated with modern controlled air (30.1\%), complete burning $(30.7 \%)$, protected $(29.8 \%)$ and well maintained incinerator $(28 \%)$ respectively (Table 2). 


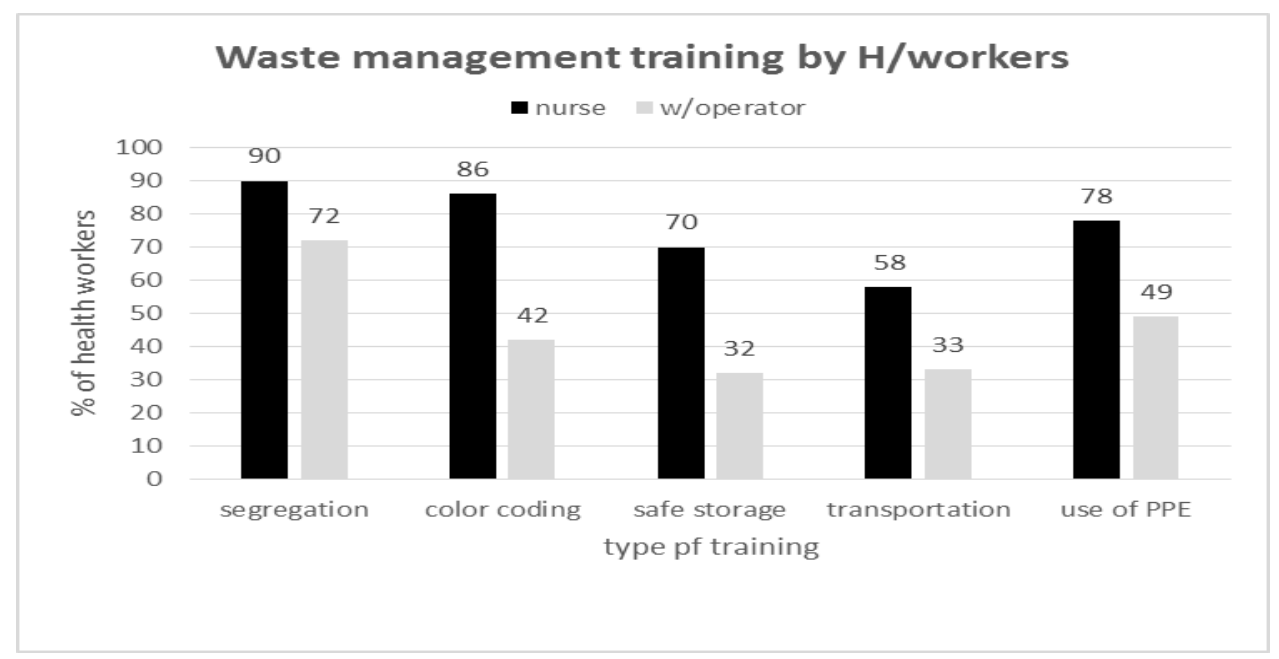

Figure 3: Training on waste management

Table 3: Institutional factors that influence waste disposal guidelines adherence

\begin{tabular}{|c|c|c|c|c|c|c|}
\hline \multirow[t]{2}{*}{ Institutional factors } & \multicolumn{3}{|c|}{ Adherence $(n=263, \% *)$} & \multicolumn{3}{|c|}{ Bivariate analysis } \\
\hline & Full & Partial & None & $\chi^{2}$ & $\mathrm{df}$ & $\mathbf{P}$ value \\
\hline \multicolumn{7}{|l|}{ Type of Incinerator } \\
\hline Modern controlled air & $37(30.1)$ & $86(69.9)$ & 0 & 41.768 & 4 & $<.001$ \\
\hline Small excess air & $6(10.5)$ & $47(82.5)$ & $4(7.0)$ & & & \\
\hline Burning chamber & 0 & $76(91.6)$ & $7(8.4)$ & & & \\
\hline \multicolumn{7}{|l|}{ Incinerator burning status } \\
\hline Complete burning (to ashes ) & $39(30.7)$ & $86(67.7)$ & $2(1.6)$ & 46.106 & 4 & 0.000 \\
\hline No complete burning & $4(5.3)$ & $69(90.8)$ & $3(3.9)$ & & & \\
\hline No incinerator (n/a) & 0 & $54(90.0)$ & $6(10.0)$ & & & \\
\hline \multicolumn{7}{|l|}{ Why its burning not to ashes } \\
\hline Defective & $27(25.5)$ & $79(74.5)$ & 0 & 32.458 & 6 & 0.000 \\
\hline Small & $16(16.7)$ & $75(78.1)$ & $5(5.2)$ & & & \\
\hline Poor design & 0 & $52(89.7)$ & $6(10.3)$ & & & \\
\hline No incinerator (n/a) & 0 & $3(100)$ & 0 & & & \\
\hline \multicolumn{7}{|l|}{ Fencing of incinerator } \\
\hline Yes & $36(29.8)$ & $82(67.8)$ & $3(2.5)$ & 38.986 & 4 & $<0.001$ \\
\hline No & $7(8.6)$ & 72(88.9) & $2(2.5)$ & & & \\
\hline No incinerator & 0 & $55(90.2)$ & $6(9.8)$ & & & \\
\hline \multicolumn{7}{|l|}{ Incinerator Status } \\
\hline Good (Maintained) & $40(28.0)$ & $102(71.3)$ & $1(0.7)$ & 41.779 & & $<0.001$ \\
\hline Not good (not maintained) & $2(3.4)$ & $51(87.9)$ & $5(8.6)$ & & & \\
\hline No incinerator & 00 & $56(90.3)$ & $6(9.7)$ & & & \\
\hline \multicolumn{7}{|l|}{ Adequate waste bins } \\
\hline Yes & $34(21.7)$ & $121(77.1)$ & $2(1.3)$ & 14.852 & 2 & 0.001 \\
\hline No & $9(8.5)$ & $88(83.0)$ & $9(8.5)$ & & & \\
\hline \multicolumn{7}{|l|}{ Waste job guideline } \\
\hline Yes & $32(24.2)$ & $96(72.7)$ & $4(3.0)$ & 12.628 & 2 & 0.002 \\
\hline No & $11(8.4)$ & $113(86.3)$ & $7(5.3)$ & & & \\
\hline Staff no. effect on $W$ disposal & & & & 7.346 & 2 & 0.024 \\
\hline Yes & 13(14.8) & $67(76.1)$ & $8(9.1)$ & & & \\
\hline No & $33(17.1)$ & $142(81.1)$ & $3(1.7)$ & & & \\
\hline
\end{tabular}

Abbreviations: $\mathrm{n}$ = total number of respondents, $\mathrm{CI}$ = confidence interval; *Column percentages; fisher exact applied where counts are less than five. $p$ values 


\section{DISCUSSION}

Level of adherence to waste disposal guidelines: Adherence level was low (16.3\%) and insignificantly different among nurses and waste handlers. From this finding, compliance remains a key challenge. This concurs with two studies: World Health Organization, after assessing the situation in 22 developing countries, revealed that the proportion of healthcare facilities that do not use appropriate waste disposal methods ranges from $18 \%$ to $64 \%$ (3). Also studies conducted earlier in Kenya by Japan International Cooperation Agency and the Kenya Expanded Programme on Immunization in conjunction with WHO which revealed that the health care waste management practices in most of the health care facilities do not comply with the international requirements to guarantee a safe and environmentally sound management of HCW (13). This low adherence rates means health workers and people living within health facilities are at great risk of environmental and health hazards associated with waste, in addition to diseases.

High incidence of low birthweight births has been related to residence near landfill sites, as the occurrence of various congenital malformations (12), while Vrijheid (14) comprehensively reports health problems associated with poor management of waste. However, this could not be ascertained in this study. It is therefore necessary to carry out a study linking poor treatment and disposal of clinical waste to purported health outcomes in Kenya. In adherence to the seven waste disposal guidelines, the respondents positively influenced correct storage of waste and use of person protective equipment. The result in this study is typified by the shortcomings associated with use of infectious waste guidelines, waste segregation procedures, adoption of prevention of air pollution and appropriate waste transport. Similar situations have been reported in Iran (15), where segregation is weak and ineffective; Nigeria (16), where infectious and non-infectious wastes are collected in the same dustbin; Botswana (17), where disposal techniques vary from one centre to another. These findings show shortcomings in five of the seven waste disposal guidelines in the waste management system, and we suggest the adoption of a holistic approach to successfully manage health care waste. This indicates that the problem remains at all stages of waste management. Despite parity in full adherence level, waste handlers rated well in correct storage of waste prior to disposal, appropriate use of PPEs and using stipulated waste disposal method, while nurses did well in disposal of highly infectious waste, waste segregation, prevention of air pollution and correct waste means of transport.

Waste disposal knowledge and practices on adherence: Availability of sufficient and accurate information is fundamental step in any waste management process. This is important in understanding the generation, waste management criteria, risks and impacts (9). Both nurses and waste handlers were knowledgeable in waste segregation with most highlighting prevention of diseases, avoiding needle prick injuries and prevention of environmental pollution but minority named recycling. Method of waste segregation was significant in relation to adherence. This was confirmed descriptively when majority of those who adopted colour coding method rated full and partial in adherence. None of the respondents who utilized mixing of waste then sort thereafter; mixing then dispose and peddle bins method fully adhered. This means that with proper implementation of colour coding method of segregation, most health workers will comply with waste disposal regulation. Two previous studies reported similar results of hospitals segregating medical waste. The first, a medical waste study conducted in 1989 by the Washington Department of Ecology, reported that $85 \%$ of hospitals in Washington segregated medical waste (18), and a second survey of 955 hospitals reported that $95.4 \%$ of hospitals segregated medical waste (19). Nurses were more knowledgeable on management of highly infectious waste, infectious waste and toxic waste. This may be attributed to specialized training and practice of nurses.

Awareness on stipulated waste guidelines: Nurses were more aware than waste handlers on stipulated medical disposal guidelines and waste segregation. This can be attributed to nurses technical education and the exposure. Both are highly aware of legal implication of mismanagement of waste and of types of waste except toxic waste. Many of the participants practiced a correct waste disposal guideline that is 
separations of waste and disposal of sharps, papers and segregation at the sources. However, both reported average results in disposal of body fluids, gloves and toxics but less knowledgeable on toxic waste and types of gloves; this may justify the earlier reported poor management of gloves. However, it is important to evaluate why the management of gloves is poor among nurses. There were contrasting results in development of waste management plans, nurses approved than waste handlers. Both highly approved the use of correct waste receptors and disposal methods. The approval of the use of receptors and disposal method was expected due to the nature of their work and risk exposure.

Knowledge on waste categories, legal implication of waste mismanagement, appropriate use of PPEs and practice of separation then disposal was high. Nurses were aware of management plans and importance of segregation to avoid diseases. This finding is in line with a survey report on hospital waste management in Dhaka City, Bangladesh by PRISM (5), which stated that the nurses and staffs were aware of the health impacts of clinical wastes.

Knowledge on waste categories, legal implication of mismanaging waste, appropriate use of PPEs, separating waste then disposal; transportation was good but the converse was true to waste management plans and that segregation avoids diseases. This may be because the former are practices-based while the latter are theoretical concepts. All types of PPEs were significantly associated with health worker adherence level except gloves. Similar findings were reported by Khalaf (20) who found significant relationship between waste management and workers' wear of special clothes during work. For gloves, this can be attributed to the poor rate of management reported earlier.

Institutional infrastructure: In this study, the type of incinerator, burning status, screening and maintenance were important to adherence level. On-site incineration of hospital waste is much favored because it is seen as fast and costeffective, but its thoroughness attracts speculations and major concerns relating to design, operation and maintenance. The size of the incinerator was key to adherence; this may be because the bigger the incinerator the larger the operation and burning space. An indication that modern large incinerators conform to universally recognized design, operations and maintenance standards for clinical waste incinerators. This finding conforms to Mochungong (21) who reported that spacious and big incinerators burn waste to completeness. None of those respondents associated with poor designed incinerator fully adhered. This denotes the significance of designing. Therefore, the biggest problems in effective clinical waste management in the current study are insufficient resource and poor incinerator capacity. This conforms to Mochungong (21) in a qualitative and quantitative study on environmental exposure and public health impacts of poor clinical waste treatment and disposal in Cameroon who reported resources allocation, awareness and training and incinerator capacity as the key challenges in waste management in developing countries.

The burning status, protection and maintenance of the incinerator are also crucial; in this study, none of those associated with defective incinerator fully adhered to the guideliness. This concurs with Srishti (22) who, in a study titled; Medical Waste Issues, practices and Policy; An Indian and International Perspective reported that difficulty of repair and maintenance of incinerators are key challenges often and particularly in developing countries. Complete burning means that the machine is designed, constructed and meets the required conditions and standards for well-functioning incinerator. This allows the combustion chambers for turbulence, adequate air that leads to sufficient combustion temperature and complete combustion. This finding validates a statement by U.S.E.PA, 1989 which stated that complete combustion requires sufficient air in the combustion chamber, sufficient temperatures in the combustion bed and combustion gas. In addition to sufficient time over which materials are exposed to a temperature profile, and mixing that assures good contact of the waste with the combustion air.

Protection and maintenance of incinerators are important with a third of those associated with protected and maintained incinerator fully adhering. Incinerators are like all machines age and requires regular servicing; this justifies why maintained incinerators are crucial. On the other hand, fencing of incinerators reduces damage. The supply of adequate waste bins and appropriate waste disposal guidelines was associated with 
adherence. This may be because waste bins facilitate segregation, which is a crucial factor in adherence.

Nurses were more trained on various waste management strategies than waste handlers. This may explain why nurses are more associated with adherence than waste handlers. This means the training focused only on waste generators. This finding concurs with Manyele (23) who reported that training of health care workers is the core of health care waste management programmes. The type of training was significant in relation to adherent rates. This concurs with Khalaf (20) who found a significant relationship between the hospital waste management and training of workers. There were contrasting results on the effect of staff establishment. Probably, because not all staff participate directly in the management of waste. This contrasts with Tsakona (24) who reported absence of qualified staff and insufficient training as key issues to efficient clinical waste management.

\section{REFERENCES}

1. World Health Organization. "Safe healthcare waste management". Policy paper by the World Health Organization. Waste Management. 2005; 25: 568-569.

2. Dehghani M, Azam K, Changani F, Dehghani F. Assessment of Medical waste Management in Educational Hospitals of Tehran University Medical Science. Iran. J. Environ. Health. Sci. Eng.2008, 5:131 136.

3. Bui, Thien Toan (2011). Market Analysis and developing a Competitive Marketing Strategy for selling medical solid Waste \& Wastewater Treatment equipment to Customers in Vietnam. Unpublished Master's thesis submitted to Lahti University of Applied Sciences.

4. Mwangi Mary Wambui and Maina Aggrey Daniel Thuo: Towards conceptual and theoretical foundation for identifying problems, challenges and mechanisms for municipal waste management in developing countries. International Journal of Innovation and Scientific Research, 2014 ; 2 (2): 230-25.

5. Innovative Space of Scientific Research Journalshttp://www.ijisr.issr-journals.org
6. Patil, G. V. and Pokhre1, K. "Biomedical Solid Waste Management an Indian Hospital": A Case Study. Waste Management, 2005, 25, 592-599.

7. Republic of Kenya (2009). District Medical Officer of Health (DMOH), Thika District, and "Annual reports (2009) Government of Kenya

8. Republic of Kenya (2008. Ministry of Health. "The National Health care waste management plan" (2008-2012.).

9. Karuga Agnes Wangechi, Alice Gathogo , Teresia Mbua, Nancy Ndungu, Ann Karani Retrospective study on overcrowding in Thika and Kiambu District Hospitals Medical Wards 2006 - 2007. Kenya Nursing Journal Dec, 2008;33 (2):pp 28-30.

10. Republic of Kenya (2008). District Health management Team -Thika district.

11. Snow John Small-Scale Incinerator Construction: Recommendations from the Rwanda Experience (2006). Making Medical Injections Safer. John Snow Inc

12. Republic of Kenya (2008); District Public Health Officer, Thika District "Annual reports".

13. Rushton, L. Health hazards and waste management. British Medical Bulletin, 2003, 68; 183-197.

14. World Health Organization. Wastes from health-care activities. Fact sheet No. 253. Geneva 2009.

15. Vrijheid, M. Health effects of residence near hazardous waste landfill sites: a review of epidemiological literature. Environment Health Perspective, 2000 108; 101-112

16. Taghipour, $\mathrm{H}$. and Mosaferi, M. Characterization of medical waste from hospitals Tebriz, Iran. Science of the Total Environment, 2009 407; 1527-1535.

17. Oke, I.A. Management of immunization solid wastes in Kana State, Nigeria. Waste Management, 2008; 12(25); 12-21.

18. Diaz, L. F., Savage, G. M., Eggerth, L. L., \& Golueke, C. G. Solid waste management for economically developing countries, 1996. Hercules, CA: Cal Recovery Inc

19. Turnberg, W.L. Survey of Infectious Waste Management Practices Conducted by Medical Facilities in Washington State; Washington State Infectious Waste Project, Attachment 2; 
Washington Department of Ecology: Olympia, WA, 1989.

20. Rutala, W.A., Mayhall, C.G. (1992). Medical waste. Position paper, The Society for Hospital Epidemiology of America. Infectious Control and Hospital Epidemiology, 1992:13:38-48.

21. Khalaf A. Abdul-Salam (2009). Assessment of Medical Waste Management in Jenin District Hospitals. Unpbilshed Master thesis submitted to school of Environmental Science- AnNajah National University, Nablus- Palestine,

22. Mochungong Peter, Ikome, Kuwoh (2011) Environmental Exposure and Public Health
Impacts of Poor Clinical Waste Treatment and Disposal in Cameroon. Unpublishe PhD thesis presented to Faculty of Health Sciences.

23. Srishti (1998). Medical Waste Update Campaign for Proper Medical Waste Disposal December 1998.

24. Manyele S. V. Effects of improper hospitalwaste management on occupational health and safety Africa Newsletter on Occupational Health and Safety, 2004;14:30-33.

25. Tsakona, M., Anagnostopoulou, E., Gidarakos, E. (2007). Hospital waste management and toxicity evaluation: a case study. Waste Management, 2007:27: 921-920. 